\title{
Exploration on Campus Network Construction Mechanism and Application Mode
}

\author{
Zhongbao Chen \\ Jilin Institute of Chemical Technology
}

\begin{abstract}
In recent years, accelerating the process of educational informationization and comprehensively promoting the informatization level and connotative development of educational institutions have been put forward in the National Medium and Long Term Plan for Education Reform and Development (2010-2020). Based on extensive research and repeated argumentation, this paper aims to provide corresponding solutions to the problems existing in the current network structure. On the basis of present situation, this paper puts forward the construction objectives and key contents according to the guideline, that is, overall planning and step-by-step implementation. In order to achieve the expected goals and get satisfied results, the construction mainly includes six parts -- the construction of basic hardware platform, application software service platform, high-quality education and teaching resources, security system, operation and maintenance system and information-based team.
\end{abstract}

\section{The current status and problems of the Internet}

\subsection{Existing network infrastructure}

There is a school information center in our school taking responsibility for the construction of school information which began in 2007.The main nodes of the campus network are connected by Gigabit fiber and are converged to the network center of school. There are more than 1800 information points and nearly 800 computers being connected to the network. The network center server provides services including WWW service, DNS service, FTP service, DHCP service, and external network export certification to the entire network users.

The network topology is shown as follows:

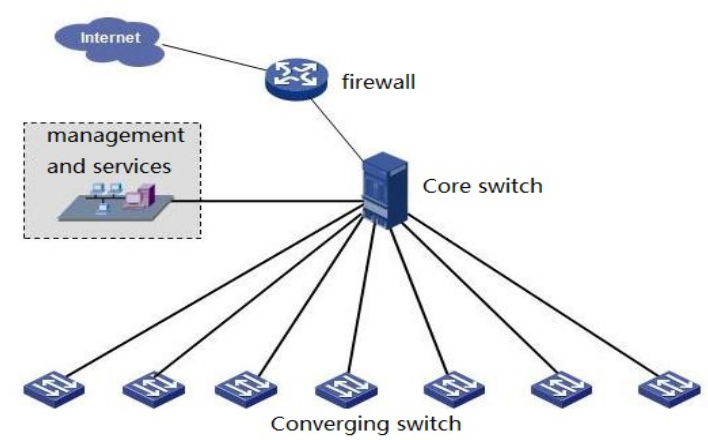

\subsection{The existing problems}

Though the school has a good foundation in the construction of digital campus, there is still some distance between the goal of the "three links and two platforms" (Establishing broadband network in each school, providing high-quality resources for each class, making everyone have network learning space, building a public educational resource service platform and an educational management service platform) proposed by the Ministry of Education.

(1) Failure to achieve full network coverage in the whole campus

At present, the school has finished the fiber-optic laying of the campus backbone network, but the network integrated wiring has not covered all classes, laboratories and training places. Thus, it needs to be improved.

(2) Failure to satisfy the system software operation requirements with current hardware configuration

Our school is the first batch of construction schools. According to the specific requirements of the three ministries and commissions (Ministry of Finance, Propaganda Department, Ministry of Education) of the state on the construction of digital campus, current hardware and equipment configuration of the school network center can no longer meet the requirements of the system software operation of the digital campus. As a result, the digital teaching resources that are under construction cannot be used normally, which affects the normal development of educational informationization. And this has become a serious obstacle and bottleneck factor restricting the construction and development of school information. Therefore, in light of the actual needs of digital campus construction for campus network, it is not only the urgent needs of the model school construction, but also the basic needs of the school 
informatization construction. All in all, it is of great significance to improve the hardware conditions of the campus network appropriately on the basis of the original campus network.

(3) Limitations of the campus information management service platform

There is no mature educational management software, network teaching platform software, and automated office system software, which affects the normal use of digital teaching resources and affects the normal development of educational informationization. The construction of digital educational resources needs to be strengthened.

\section{Construction goals}

Based on the construction of information infrastructure, focusing on the information supporting environment and connotative construction, through the construction of "three links and two platforms", we aim to enrich the information management tools, improve the resource co-construction and sharing mechanism, improve the application ability of information technology in teaching, and promote both teachers and students' information application competencies and skills.

We strive to complete the construction of educational management information system platform and education and teaching resources platform in recent 2 years, and realize the construction goals of establishing broadband network in each school, providing high-quality resources for each class, making everyone have network learning space, building a public educational resource service platform and an educational management service platform so that schools can become informationalize in education, teaching and administrative management, and finally reach digital campus construction standards, becoming a fully functional digital campus, and play a demonstration and leading role in the school information construction and application fields.

\section{Research on the content of construction}

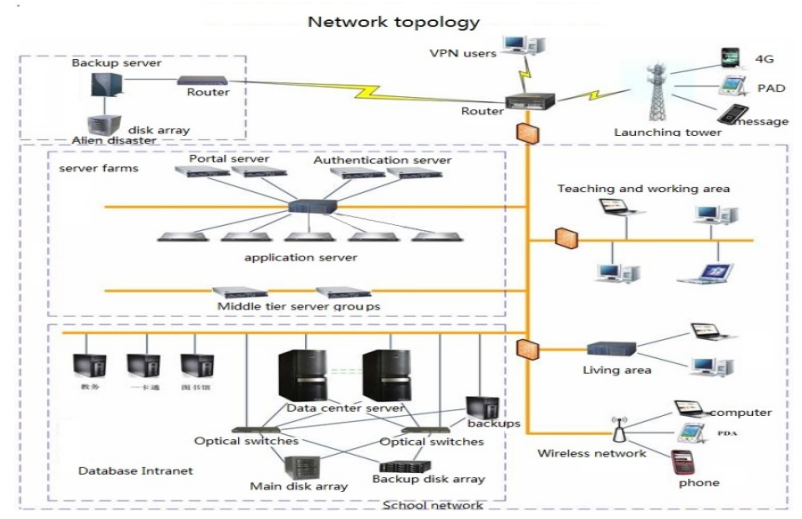

With the construction of the "three links and two platforms" as the core digital campus construction goal, with reference to relevant countries and industry standards, the main construction contents include basic hardware platform construction, application software service platform construction, high-quality education and teaching resource construction, security system construction, the operation and maintenance system construction, information-based team construction, the system security construction and the basic hardware platform construction.

\subsection{Construction of basic hardware platform}

Database storage exchange area: two professional servers are used to cluster and serve as data center servers. The storage methods are FC runtime storage and backup storage of SATA disks. Storage requires FC interface and IPSan interface, that is, storage for data center database through FC connection. If other servers need to connect to the database server of the new system through IPSan and connect to the storage through the FC port, the databases of other existing systems can also be placed in the intranet of the school database. Server cluster services mainly include: portal, identity authentication, data center application server, using two rack servers or blade servers to virtualize servers and make soft clusters through software such as WMWARE;

The middleware server, in order to enhance the security of the application system to access the database, the single-row middleware server layer, using two high-end rack servers or blade servers, virtualizing the server through software such as WMWARE and making a soft cluster so that it can be virtualized into multiple points. Therefore, any application (new or later) that wants to visit the database needs to be accessed through the middleware server. The application server group uses multiple rack servers or blade servers to virtualize servers and soft clusters through software such as WMWARE.

In the area of teaching, working and living, the way of combining wired network with wireless network will reduce erection costs and improve operational effects. Using load balancing switch or other balancing strategies ensures that mobile devices such as notebook computers, iPads and other wireless devices can access campus resources normally.

Off-campus mobile devices are connected to mobile devices such as $4 \mathrm{G}$ mobile phones, iPads, and mobile phones (SMS) through mobile platforms (services provided by mobile providers such as China Mobile, China Telecom, and China Unicom). Strategic incremental replication of critical business data over the IP network between the data center and the disaster recovery center enables offsite backup of data and rapid recovery of data in the event of an unexpected disaster.

Suppose that every 2 people simultaneously use the network to enjoy 1 megabyte of bandwidth. We need to expand the export bandwidth to meet the needs of the school's digital campus construction for export bandwidth. Based on the existing Gigabit fiber and network center computer room of the school, the internal network of the teaching place will be integrated and wired, and the supporting teaching equipment will be added to provide a multimedia teaching environment.

On the basis of the existing network equipment, the network core switch, part of servers, network security 
equipment, and teacher machine, we need to complete the related supporting environment construction so as to meet the needs of the storage of campus resources, the security of the intranet and the high-speed exchange of large amounts of data.

\subsection{Construction of application software service platform}

\subsubsection{Update the school portal website}

The unified identity authentication and authorization platform mainly provides centralized identity authentication and authorization services for each application system. The user realizes single sign-on through the unified information portal to improve the security of the application system of the information management system. By specifying the corresponding centralized authentication technical specifications, a unified application system user management interface is provided, and finally centralized management of all new system user authentication is realized.

\subsubsection{Construction of informationalized standard system}

In accordance with the actual situation of the school, a set of informatization management standard system conforming to the school itself, including information standards, code coding standards, technical standards, management norms, etc., is provided to provide basic conditions for information exchange and resource sharing, and to ensure that information is collected and exchanged. There is a unified, scientific and standardized classification and description in the transmission process to ensure the orderly construction, use, management and maintenance of the information management system.

\subsection{The construction of high-quality teaching resources}

(1) Establish a school education resource center based on the basis of the development and construction of digital resources, and enrich the digital education and teaching resources of the whole school through various ways. Build a public learning platform to enrich the content of the course and expand the scope of application. Establish a new network learning model to form a learner-centered learning framework. Teachers are encouraged to produce high-quality courses and web-based courses, and build digital libraries, video and audio libraries, courseware libraries, excellent training cases, reform and innovation courses, and provide high-quality learning resources for teachers, students and others in the areas of online learning, mobile learning and online counseling.

(2) Two new teaching skills training rooms are built to be used in the construction of high-quality courses in schools, and the network sharing of high-quality courses resources can be achieved quickly. They are used in Microteaching to correct and train teachers' teaching skills. They are used to record the courses of "famous teachers' network classes" and to carry out long-distance training and excellence by means of live or on-demand broadcasting. The production and production of quality teaching resources.

\subsection{Safety system construction}

Information security should be considered and designed from hardware system security, software system security, application management security and other aspects.

\subsubsection{Network system security}

Considering physical layer security technology and network layer security technology, and physical layer security technology is considered from the aspects of campus network environment security, network operation equipment security, physical isolation of top-secret data, etc. Network layer security technology: between database server and application server, application server, WEB server and campus network add necessary firewall for security filtering, and add intrusion detection security technology, installing anti-virus software in server and user terminal, and installing network virus monitoring and cleaning software.

\subsubsection{Software system security}

Considering the operating system and application software, the operating system is the basis of normal operation of all computer terminals, workstations and servers, and the security of the operating system is very important. The key server should adopt the server version of the operating system. There are many security vulnerabilities in the operating system because of the design and version problems. In order to strengthen the security management of the operating system, it is necessary to strengthen the security from the aspects of physical security, login security, user security, file system and printer security, registry security, RAS security, data security, application system security and so on. Application software system security is designed through the data access strategy, data encryption, user control, system and information backup, system and information recovery, $\log$ system and other aspects of information security.

\subsubsection{Database security}

The access and operation of database are verified and authorized.

\subsubsection{Data transmission security}

Data transmission can be carried out by means of HTTPS encrypted transmission. The main function of Https protocol can be divided into two kinds: one is to establish an information security channel to ensure the security of data transmission; the other is to confirm the authenticity of the website. In order to ensure the confidentiality and 
integrity of data transmission, identity authentication can also be used for dial-up user access.

\subsubsection{Data storage security}

In order to prevent the abnormal damage of storage devices, the disk fault-tolerant array composed of hot-pluggable SCSI hard disks can be used to backup the system in real-time by RAID5.

\subsubsection{System log security}

The log system has the function of comprehensive data recording and automatic classification and retrieval. In this system, the log will record all the operations performed in the process from the time a user logs in to the time he exits the system, including the operation of the database and the use of system functions. The logs contain IP addresses, operation types, operation objects and operation execution times of the operating host of the user for future audit verification.

\subsection{Operation and maintenance system construction}

\subsubsection{Work system}

Improving the reasonable working system is the key to the success of digitalized campus information. In order to complete the construction of digital campus smoothly under the circumstances of heavy tasks and urgent time, it is necessary to establish a complete working system to ensure the healthy and orderly development of information construction. We should continue to strengthen organizational leadership, and establish a reasonable division of labor and clear responsibilities for the promotion of information coordination mechanism, provide funding and site security, and promote the healthy development of information technology.

\subsubsection{Management organization}

The leading group of digital campus information construction is the leading organization responsible for planning, organizing and coordinating work. As the daily management organization of the project construction, the leading group of digital campus information construction is responsible for the implementation and guidance of the information construction plan, and supervises and urges departments at all levels to actively participate in the information construction work.

\subsubsection{Management mechanism}

Establish and improve the organization and management system of information work, project management system, operation and management rules and regulations. We should make unified provisions on information work so as to make information construction work more orderly.

\subsection{Information team building}

(1) Participate in various computer technology training organized by the Ministry of education.

(2) Plus provincial educational technology training

(3) Participate in technical training for industry organizations.

(4) Organize all staff training in the school so that all teachers can skillfully use all the applications provided by information construction.

\subsection{Institutional guarantee}

We should make plans for the school information construction, and further clarify the functional departments, and carry out the post responsibilities.

Establish and improve the relevant management system. Strengthen process management, implement target management responsibility system, implement regular meetings, periodic inspection, periodic summary system to ensure the orderly progress of information construction, the whole process has rules to follow. Establish a guarantee and incentive mechanism to ensure the long-term development of school education informatization.

\section{Expected results of construction}

\subsection{Build a perfect educational management information platform}

To realize the comprehensive integration of application service platforms such as educational management informatization, educational teaching informatization, educational scientific research informatization and student learning informatization, so as to make the level of school educational management informatization reach the leading level in the province.

\subsection{Build a perfect public service platform for educational resources}

Ensuring that the platform has the function of opening and sharing high-quality educational resources has become an important node of high-quality educational network teaching resources.

\subsection{Realizing the goal of "three links" in an all round way}

We should resources, classes, and cyberspace. The ability of teachers and students of applying educational information resources has been greatly improved. Digital campus has become an important means of improving the quality of education and teaching. Information construction especially digital campus construction plays a leading and exemplary role in educational institutions. 